\title{
Spectroscopic Investigation on the Interaction between 4-Amino Salicylic Acid (PAS) with Bovine Serum Albumin (BSA)
}

\author{
Mamali Priyadarshinee, Bairagi C. Mallick* \\ Department of Chemistry, Ravenshaw University, Cuttack-753003, Odisha, India
}

\begin{abstract}
PAS (4-amino salicylic acid) is a potentialantimicrobial drug used for the treatment of Mycobacterium tuberculosisdrug resistance. Its interaction with bovine serum albumin (BSA) is important to understand the mechanism of drug-protein interactions and its effectiveness to treat the drug resistance. The binding of PAS with BSA, investigatedby UV-visible and fluorescence measurements clearly indicates the conformational stability of the protein, Further, FT-IR and CD spectroscopic methods support the results with inceasing secondary structure content of the protein in the presence of drug.
\end{abstract}

Keywords: Bovine serum albumin (BSA), 4-aminosalicylic acid (PAS), fluorescence, FT-IR and CD spectroscopy.

\section{Introduction}

Mycobacterium tuberculosis, the human pathogen causing tuberculosis claims nearly about 2 million lives each year, and it is estimated that one third of the total global population is latently affected by this bacilli.[1] The alarming rise of multi drug resistant in the treatment of $M$. tuberculosis can be overcome through the production of new anti-uberculosis agents, which can be better understood by determining the pharmacodynamic and pharmacokinetic properties. Unlike many drugs, para amino salicylic acid (PAS) is an antimicrobial drug used for multidrug resistant tuberculosis treatment. PAS has been clinically used as a prodrug to combat the pathogenesis of $M$. tuberculosis through the depletion of tetrahydrofolate (THF), which is essential for protein synthesis, resulting in inhibition of bacterial growth and death.[2-4]It also acts as NF- $\kappa$ B (nuclear factor-kappa B) inhibitor and free radical scavenger.

Bovine serum albumin is one of the most important proteins in the circulatory system, accounts for about $60 \%$ of the total plasma protein. Albumin constitutes the main protein fraction ( 5\%) in blood plasma ( as albumin contains both basic and acidic groups, it can bind basic and acidic drugs. Serum albumin acts as a major depot and transport protein, capable of binding and delivering drug or other endogenous and exogenous compounds to the target organs. [5,6] Among the serum albumins, Bovine Serum Albumin (BSA), with a molecular weight $68,000 \mathrm{~g} \mathrm{~mol}^{-1}$ has wide range of physiological functions.[7-10] BSA contains 583 amino acids in a single polypeptide chain, 17 disulfide bridges and one free - $\mathrm{SH}$ group, which can cause it to form a covalently linked dimer.BSA contains two tryptophan (Trp) residues, one located on the surface of the molecule (Trp-134) and the other at the bottom of hydrophobic cleft between domains I and III(Trp-212). It also has a high degree of $\alpha$-helical content lying on the surface of hypothetical cylinder with an open channel running along the axis.BSA is known to exhibit a very high conformational adaptability to large variety of ligands. [11,12] Thus, the present study was aim to investigate the in-vitro interaction of PAS with BSA, and its conformational stability through UV-visible, fluorescence, FT-IR and CD spectriscopic methods. The results obtained will be correlated to the in-vivo mechanims of drug-protein interations and the possible improved pathways of treatments.

\section{Materials and Methods}

Fatty acid free Bovine Serum Albumin (BSA, purity is > $96 \%$ as stated by manufacturer) and 4-amino salicylic acid (PAS) were purchased from Sigma Aldrich Company, USA. The buffer (Tris-HCl)wasobtained from MP-Biochem Ltd. (India). The protein was used without further purification.

\subsection{UV-visible Measurements}

The stock solutions of BSA $\left(5 \times 10^{-3} \mathrm{M}\right)$ and drug 4-Amino Salicylic Acid $\left(5 \times 10^{-3} \mathrm{M}\right)$ based on their molecular weight 66.5 KD and $135.14 \mathrm{~g} \mathrm{~mole}^{-1}$ respectively were prepared in $50 \mathrm{mM}$ Tris-HCl, $0.5 \mathrm{M} \mathrm{NaCl}$ buffer solution at $\mathrm{pH}$ of 7.2.All solutions were prepared in deionised milli-Q water and degassed before used for the experiment. Each time the sample solutions were prepared freshly for each measurement.The absorption spectra were recorded using a Carry-100 UV-visible spectrophotometer with quartz cuvette of path length $1-\mathrm{cm}$. The absorption was monitored by keeping the protein concentration $(10 \mu \mathrm{M})$ constant and varying the concentration of drug from 0 to $50 \mu \mathrm{M}$. Baseline was corrected using $50 \mathrm{mM}$ Tris- $\mathrm{HCl}, 0.5 \mathrm{M} \mathrm{NaCl}$ buffer solution at $\mathrm{pH}$ of 7.2 .

\subsection{Intrinsic Fluorescence Measurements}

The fluorescence measurements were recorded with a Cary Eclipse Spectrofluorimeter (Agilent)at different concentration of drug $(10-50 \mu \mathrm{M})$ keeping the concentration of protein $(10 \mu \mathrm{M})$ constant. The emission intensity of tryptophan residues of proteins at $340 \mathrm{~nm}$ (excitation wavelength $295 \mathrm{~nm}$ ) was monitored using drug as quencher with increasing concentrations. 


\section{International Journal of Science and Research (IJSR) \\ ISSN (Online): 2319-7064}

Index Copernicus Value (2013): 6.14 | Impact Factor (2015): 6.391

\subsection{Circular Dichroism}

CD spectra was recorded on a JASCO-J815 spectropolarimeter (JASCO, Japan) using a $0.1 \mathrm{~cm}$ quartz cell. CD spectra of BSA in the presence and absence of PAS were recorded from $190 \mathrm{~nm}$ to $260 \mathrm{~nm}$. The overall concentration of BSA was kept at $10 \mu \mathrm{M}$ while the molar ratios of BSA to PAS ranged from 1:1 to 1:5.The raw data were used to calculate mean residue ellipticities $[\theta]_{222}$ using equation:

$$
[\theta]_{222}=100 \times \theta \times M w /(\mathrm{cln})
$$

Here, c is the protein concentration in molar, and 1 the cell pathlength in $\mathrm{cm}, M$ wis the molecular weight of BSA and n is the number of amino acid residues in BSA. The factor of 100 converts pathlength in meters.

\subsection{Fourier Transformed Infrared Spectroscopy}

The FT-IR spectra of BSA solution $\left(5 \times 10^{-3} \mathrm{M}\right)$ was recorded on a Burker vector 22 Spectrophotometer (Burker, Ettlingen, Germany) equipped with a Germanium attenuated total

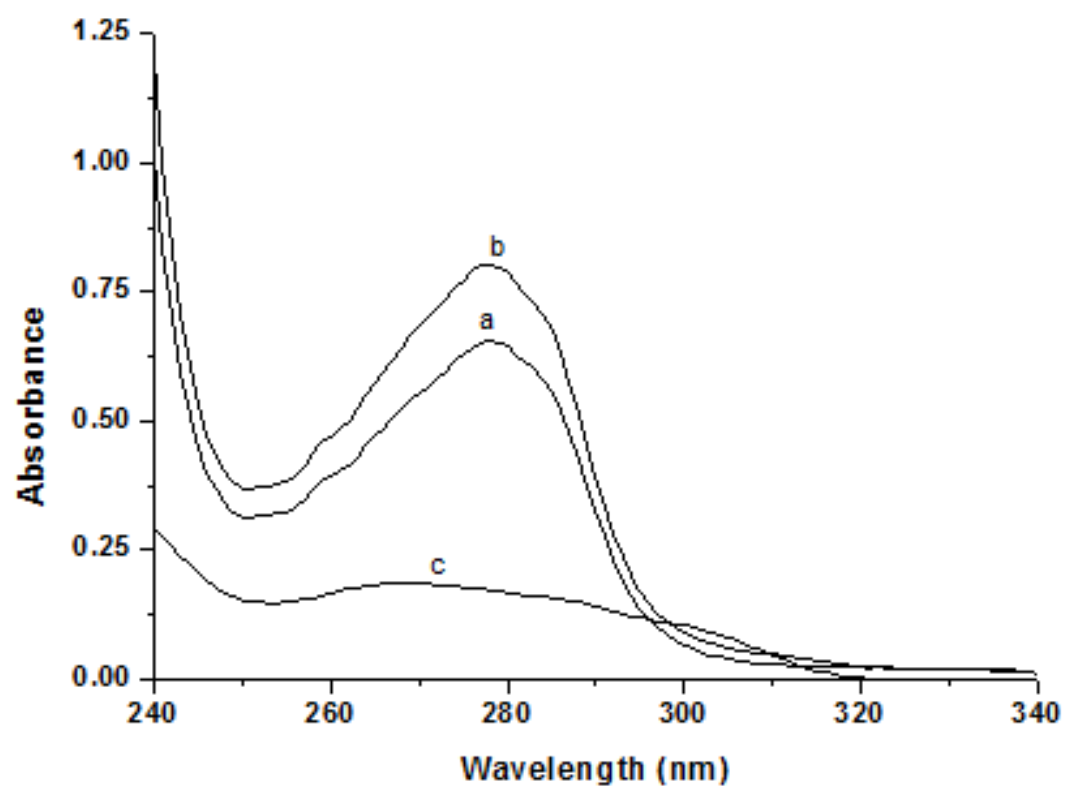

Figure 1: UV-vis absorption spectra of BSA (a), BSA-PAS (b)and PAS (c) at $298 \mathrm{~K} . \mathrm{c}(\mathrm{BSA})=10 \mu \mathrm{M}$ and $\mathrm{c}(\mathrm{PAS})=50 \mu \mathrm{M}$ respectively.

\subsection{Fluorescence emission spectraof BSA in the presence of PAS}

Generally, the fluorescence of protein is due to the intrinsic fluorescence of three molecules present in the protein, i.e., Trp, Tyr, Phe residues. Actually, the intrinsic fluorescence of many proteins is mainly contributed by tryptophan alone because of very low quantum yield of Phe, and the fluorescence of Tyr is almost quenched via energy transfer to Trp, if Tyr is ionised near an amino or carboxyl group. In order to confirm the interaction between BSA and PAS is carried by keeping the concentration of protein constant while varying the concentration of the drug. Before to record the fluorescence intensity of BSA in the presence of drug, the fluorescence intensity of 4-aminosalicylic acid is measured at excitation wavelength $295 \mathrm{~nm}$. The drug used in this study is emissive. It has an emission wavelength at $390 \mathrm{~nm}$. The emission intensity of BSA is found to be reflection accessory and a KBR beam splitter. FT-IR spectra of free BSA solution were acquired by subtracting the absorption of the buffer solution from the protein solution and a difference spectrum was obtained by subtracting the spectrum of PAS solution from that of BSA-PAS solution.

\section{Results and Discussion}

\subsection{UV absorption spectra of BSA in the presence of PAS}

The absorption maximum of BSA at $278 \mathrm{~nm}$ is characteristic absorption of nonpolar residues like tryptophan (Trp) and tyrosine (Tyr) in BSA. The absorption spectra of BSA alone and its complexation to PAS upon interaction is shown in the Fig.1. It is evident that the drug has no absorbance at 276 $\mathrm{nm}$, which is typical for tryptophan resisde. The absorbance upon complexation with BSA, there is increases in absorbance at $276 \mathrm{~nm}$. Thus, the complexationdue to drug binding results in conformational changes in BSA at physiological pH 7.2. 


\section{International Journal of Science and Research (IJSR) \\ ISSN (Online): 2319-7064}

Index Copernicus Value (2013): 6.14 | Impact Factor (2015): 6.391

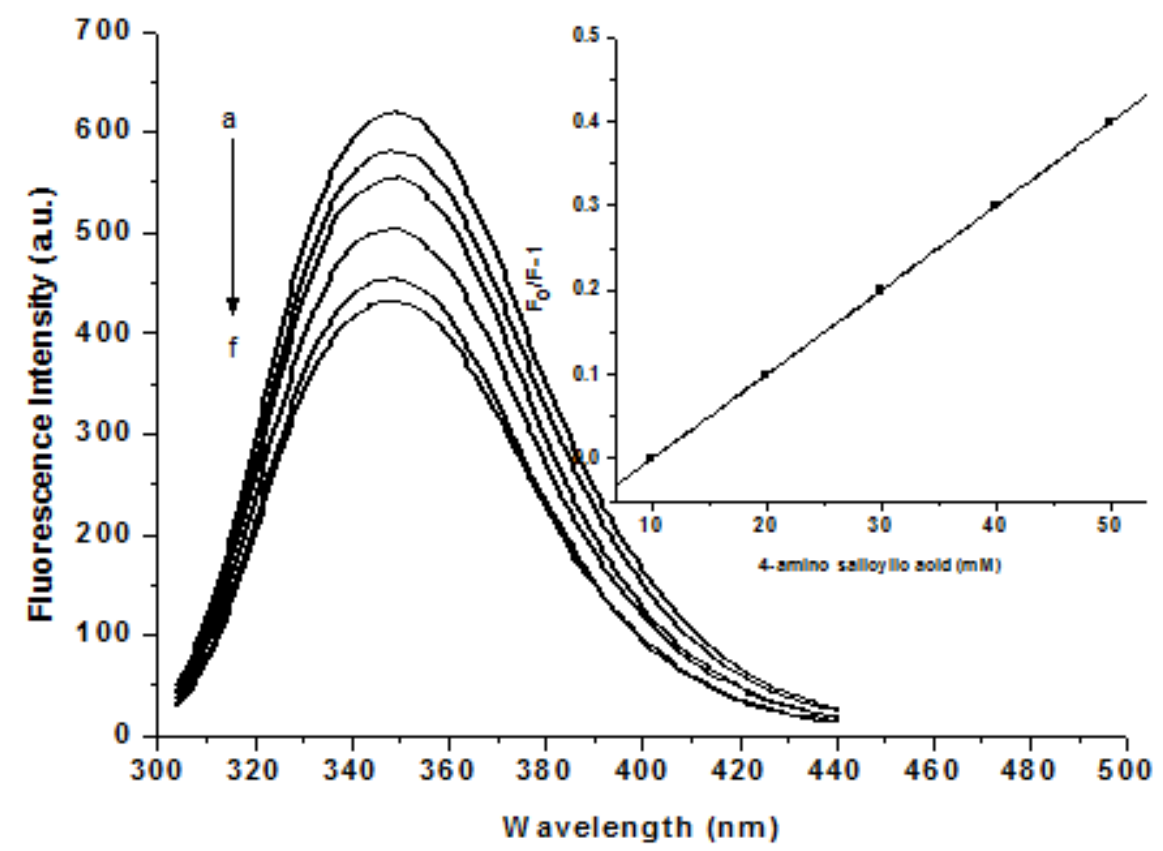

Figure 2: Fluorescence quenching spectra of BSA (a) at pH 7.2 and in the presence of increasing concentration of PAS from $10 \mu \mathrm{M}$ (b), $20 \mu \mathrm{M}$ (c), $30 \mu \mathrm{M}$ (d), $40 \mu \mathrm{M}$ (e) and $50 \mu \mathrm{M}$ (f) respectively. The protein concentration was fixed at $10 \mu \mathrm{m}$ for all experiments.

\subsection{Fourier Transformed Infrared Spectroscopy}

To observed the effects of PAS on the BSA confirmation, FT-IR measurements were performed and shown in Fig.4. The FT-IR spectra of BSA at pH 7.2 shows an amide I band around $1600 \sim 1700 \mathrm{~cm}^{-1}$ and amide II band around 1548 $\mathrm{cm}^{-1}$. Any change in these band range, indicatesthe change in protein secondary structural. [13]In Fig. 3,the amide I band and amide II bands for free BSA were found at 1649 $\mathrm{cm}^{-1}$ and $1545 \mathrm{~cm}^{-1}$, respectively. However, BSA on complexation with PAS, the amide I band shows almost no change but the amide II band shows a peak at $1546 \mathrm{~cm}^{-1}$ and a new peak at $1523 \mathrm{~cm}^{-1}$. This may be due to the change in protein secondary structure after interraction with the drug PAS at physiological pH 7.2.

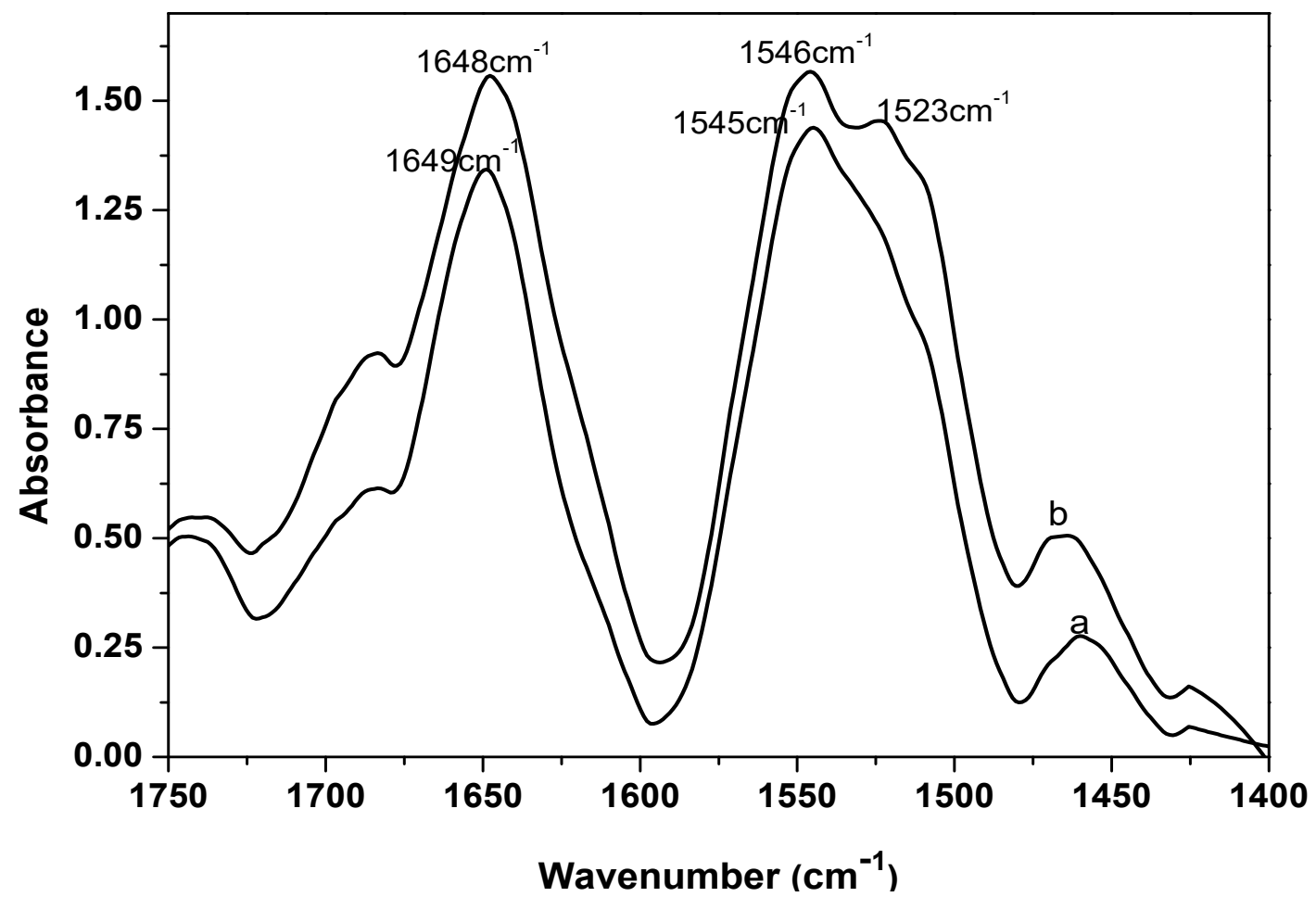

Figure 3: FT-IR spectra of BSA and BSA-PAS complexes. $c(B S A)=10 \mu \mathrm{M}$ (a) and BSA-c(PAS)=50 $\mu \mathrm{M}$ (b) at physiological $\mathrm{pH} 7.2$. 


\section{International Journal of Science and Research (IJSR) \\ ISSN (Online): 2319-7064}

Index Copernicus Value (2013): 6.14 | Impact Factor (2015): 6.391

\subsection{Circular Dichroism}

Circular dichroism (CD) is an important analyticl method used to monitored the protein conformational changes. The near UV-CD spectra of fatty acid free BSA (Fig. 4)and its complexation with PAS were used to monitored the conformational changes of BSA and its interaction with PAS at physiological $\mathrm{pH}$ 7.2. The CD spectraof BSA shows two negative bands at $208 \mathrm{~nm}\left(\pi \rightarrow \pi^{*}\right.$ transition) and $222 \mathrm{~nm}$ $\left(n \rightarrow \pi^{*}\right.$ transition ) respectively, which are characterstic of $\alpha$ helix protein. The binding of PAS to BSA shown an increase in negative molar ellipticity from $10 \mu \mathrm{M}$ to $50 \mu \mathrm{M}$. This indicates the change in protein secondary structure upon PAS binding.

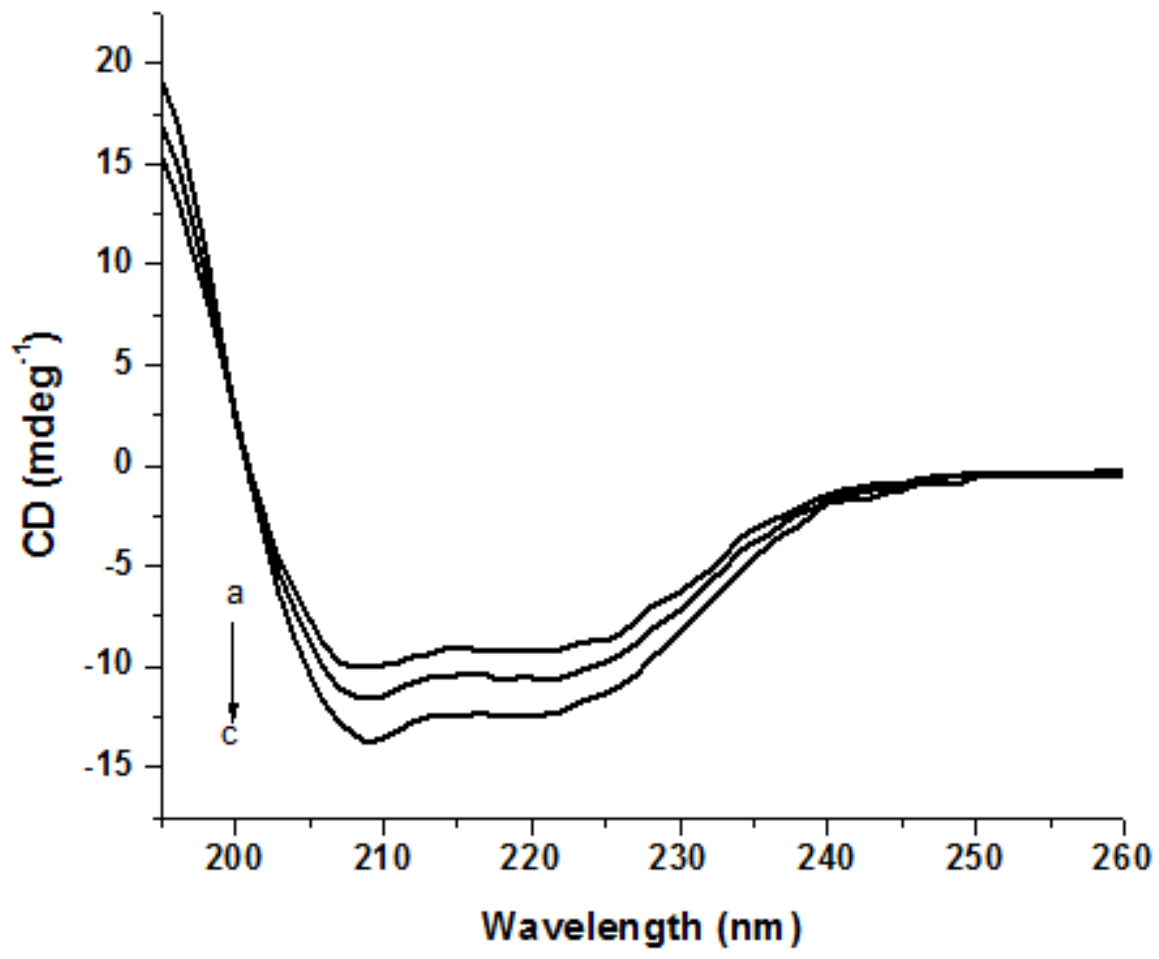

Figure 4: Near UV-CD spectra of BSA (a) and in the presence of different concentrations of PAS at pH 7.2. $\mathrm{c}(\mathrm{BSA})=5 \mu \mathrm{M}$ and $\mathrm{c}(\mathrm{PAS})=10 \mu \mathrm{M}$ to $50 \mu \mathrm{M}$. For clarity, only $10 \mu \mathrm{M}$ (b) and $50 \mu \mathrm{M}$ (c) spectra have been shown.

\section{Conclusions}

The interaction of PAS with BSA have been investigated using spectroscopic methods. The UV absorbance and fluorescence quenching experiments results clearly indicate the significant interaction of the drug with BSA through the change in conformational stability. Further, the FT-IR and $\mathrm{CD}$ measurements confirms the interaction of the drug and conformational changes through the secondary structuration.

\section{Acknowledgements}

We are thankful to UGC, New Delhi, India for financial support through Major Research Project (MRP) to BCM [F.No.41/283/2012 (SR)].

\section{References}

[1] J. Zheng, E. J. Rubin, P. Bifani, V. Mathys, V. Lim, M. Au, J. Jang, J. Nam, T. Dick, J. R. Walke, K. Pethe, and L. R. Camacho, J. Biol. Chem. 2013, 288 (32), 2344723456.

[2] Nopponpunth, V., Sirawaraporn, W., Greene, P. J., and Santi, D. V. J. Bacteriol.1999,181,6814-6821.

[3] Rengarajan, J., Sassetti, C. M., Naroditskaya, V., Sloutsky, A., Bloom, B. R., and Rubin, E. J.,Mol. Microbiol. 2004,53,275-282.
[4] Ratledge, C., and Brown, K. A., Am. Rev. Respir. Dis. 1972, 106,774-776.

[5] Zhao XC, Liu RT.,Environ. Int., 2012, 40, 244-255.

[6] Beauchemin R, N'Soukpoe-Kossi CN, Thomas TJ, Thomas T, Carpentier R, Tajmir-Riahi HA., Biomacromolecules 2007, 8, 3177-3183.

[7] Brunaldi K, Huang N, Hamilton JA .,J. Lipid Res.,2010, 51, 20-131.

[8] Shim Y. Y., Reaney M. J. T., J. Agric. Food Chem. 2015, 63, 1099-1106.

[9] Yamashita MM, Wesson L, Eisenman G, Eisenberg D., Proc. Nalt. Acad. Sci., USA1990, 87, 5648-5652.

[10] Bal W, christo Doulou J, Sadler PJ, Tucker A., J Inorg Biochem1998, 70, 33-39.

[11]Zhou N, Liang Y-Z, Wang P., J Phot. Photobio A Chem. 2007, 185, 271-276.

[12] Shang L, Jiang X, Dong S., J Photochem Photobio A Chem2006, 184, 93-97.

[13] Purcell M., Neault J.F., Malonga H., Arakawa H., Carpentier R., TajmirRiahi HA., Biochim Biophys Acta 2001, 1548,129- 138. 